\title{
The value of railway heritage for community development
}

\author{
U. Llano-Castresana ${ }^{1}$, A. Azkarate ${ }^{2}$ \& S. Sánchez-Beitia ${ }^{1}$ \\ ${ }^{1}$ Departament of Architecture, University of the Basque Country \\ UPV/EHU, Spain \\ ${ }^{2}$ Facultad de Letras de Vitoria-Gasteiz, University of the Basque Country \\ UPV/EHU, Spain
}

\begin{abstract}
The progressive modernization of the railway infrastructure has caused many lines (both active and disused) to progressively leave apart a series of railway buildings (some of them, architectural and civil engineering elements of great value), with their use already obsolete or without the main function which they were intended for. The high cost of maintenance leads them to a progressive state of margination, neglect and decay. This paper discusses various elements of the railway heritage, particularly the stations and their auxiliary buildings, their context and the way to put them in value, according to the needs of the society and the territory in which they are set. The railway heritage represents potentially an added value that can be assumed, correctly managed, be the drive shaft of a new function that ensures the future of the stations and serve as the main driving force and enhancer for the active development of a community or territory. For this, the analysis of the territorial strategy, the new energetic and social model and the existing potential in the closer areas will play a key role in achieving, through a new strategic role demanded by society, a self-management of architectural (constructed) railway heritage.

Keywords: railway heritage, regional development, active resources, territorial structuration, potential forces of the surroundings, energetic model, social model.
\end{abstract}

\section{Introduction}

Railways are one of the most valuable heritage assets from the second industrial revolution, essential engine of an emerging economy, the standard of an incipient 
social change that was pushes through capricious valleys and rugged mountains to transport minerals from and to distant locations and to bring people from diverse places led to a new way of seeing the world and understanding it. But the railways are also part of our heritage and our memory, silent witnesses of our closest industrial past and the link to a future in which inter-territorial mobility will increase progressively based on social, economic and environmentallyfriendly transportation models [1], which seem to be fundamental, in a society increasingly aware that this is possible.

From the first third of the last century, the application of nonsustainable energy policies that have made us overly dependent on fossil fuels together with thousands of miles of paved roads, resulting in an abandonment of railway lines that once enjoyed great vitality and were main communication arteries, now left at the mercy of time and forgetfulness in a matter of few decades. Now they are brought to us as a new alternative to an already exhausted social, territorial and energetic model.

The progressive modernization of railroad resources has caused many railway lines (both active and disused) to progressively dispense with a series of railway buildings, landmark buildings (stations, power plants, garages, abbr.) and auxiliary elements whose use has become obsolete or no longer fulfil the main function for which they were intended for at the time. They are architectural and civil engineering elements of great value, and above all, they represent a great potential for generating active resources for our society.

All these infrastructures provide an opportunity to reinvent ourselves, already detached from past models of urban sprawl [2] (which are clearly being eradicated from most countries in Europe, according to the growth-model rethinking and re-development process in which we are involved at the present), starting from traces of our legacy and acting conscientiously. These items can become an icon of a new way of reusing spaces with an value added, giving life back to the heritage, turning it into a useful and socially functional space: the revaluation of assets by allowing them to be self-managed, and therefore, to have a future in this globalized society in frantic and continuous change, but which does refuse to relinquish its cultural wealth, own character, heritage legacy and identity.

\section{The Basque railways heritage}

Since 1927 the construction of the Basque railway network was almost complete. At that time, Basque railroads added up to a total of 825 kilometers, divided into 310 kilometers of broad gauge and 515 kilometers of metric gauge. This structure and its layout have remained virtually unaltered throughout the twentieth century, but since 1953, we have witnessed the closure of over $320 \mathrm{~km}$ of line [3]. Currently, the length of railroad lines in disuse in the Basque Country represents more than half of the active lines' stretch. And although some of them are still strategically essential axes of inter-territorial communication [4] for the development of a "new sustainable territorial model", their situation is very precarious, to the point of being at serious risk of disappearance. In addition, the 
aforementioned continuous modernization of the effectiveness of the current lines in use, in order to be more competitive, is leaving the vast majority of railway stations and auxiliary buildings empty of any function, which leads to the problem of asset management and its maintenance and leaves the existence of such iconic buildings as railway stations in a delicate situation.

Therefore, in the railway we find a field in which the need of a deep reflection and a change of mentality is palpable. We have a heritage that we do not use, resources that they do not produce, or that we are not able to make them to produce... this, for any society, regardless of the current economic situation, is a luxury we cannot afford. So, we can try to dig into the study of what this railway heritage may offer to society, not only as historical-cultural and artistic legacy, of what was once our society, not only as museum pieces as a vague memory with that one day a certain collectivity was identified. Because today more than ever, it is palpable that another model is possible, do not renounce to advance from the maturity that gives information and knowledge.

In this presentation, we will focus on the built railway heritage and more specifically on the stations and their putting in value (PV). We will suggest various theoretical guidelines to follow in this process and we will present a theoretical revaluation exercise applicable to various disused lines or railroad stretches of the Basque Country, such as the Urola Railway (RW), Bidassoa RW, the Plazaola RW, Vasco-Navarro RW or to those which are in use, for instance the Amorebieta-Bermeo RW, among others. This model could be extrapolated to European lines with similar characteristics.

\section{Approaching to the study model}

The whole Spanish state was never up to the main European countries' standards of the time (Belgium, the UK, France...) in terms of extent of rail network. From 1845 to $1855,475 \mathrm{~km}$ of railway were opened to the public. Until 1868, another $4899 \mathrm{~km}$ were put in operation, but from 1868 to 1876 the process was halted (due to Carlist wars) and only $382 \mathrm{~km}$ were built. However, we must emphasize the role played by the province of Gipuzkoa from 1863 until 1926, when the Urola Railway, which was the last, was opened. In those years, Gipuzkoa had $386 \mathrm{~km}$. of railway system. The province was equipped with a truly enviable communication system, with 196 meters of rail per square kilometer of its territory and 1.28 meters rail per inhabitant. In other words, Guipuzcoa had one of the most dense rail networks in Europe [5].

At the beginning of last century, the railroad structural organization in the Basque Country was already established and it was configured mainly around two interests: on the one hand the control of national and international major traffic access, and on the other hand the output of Basque steel products and raw material supply for the production industry, for which the railroad was the most suitable way of transport. Hence, a narrow rail network that would overcome the difficulties entailed by the general standard width lines was organized, determining a model that was extended from west to east, from Leon and Santander to Hendaye, on the Bilbao-San Sebastian-Hendaye axis. This network 
was completed with the main axis that, from the very heart of the territory, gave access to the Ebro valley (Malzaga-Lizarra or Vasco Navarro RW.), giving form this way to the so-called "Y". Almost all existing stretches represent the legacy of an extensive railway network, strongly determined by the topography and the interests of the business grid, to whom it helped develop greatly. But since 1953, many of these lines were begun to be dismantled (fig. 1), due to the higher profitability and competitiveness that road transport back then, among other reason. Only in these lines, we had more than $320 \mathrm{kms}$ of railway tracks, 60 stations, and more than $15.000 \mathrm{~m}^{2}$ covered spaces, as shown in table 1 . A more substantial asset to use as a resource. (If we add to these data, stations from active lines, that are running out of any particular use, we have a wide field of resources to try to manage and exploit). We have to "reuse" this legacy and provide it with new features that society demands, using the "profitability" and

Table 1: Number of stations + auxiliary buildings, the kilometers of the line and an approximate minimum useful space existing in disused lines, in part of the Basque Autonomous Community (CAV) and Navarre.

\begin{tabular}{|c|c|c|c|}
\hline Railway Lines & Num of Buildings & Floor area $\left(\mathrm{m}^{2}\right)$ & Line length $(\mathrm{km})$ \\
\hline Vasco-Navarro & $18+25$ & 6,700 & 143 \\
\hline Urola & 15 & 5,300 & 36 \\
\hline Plazaola & $15+5$ & 2,800 & 94.6 \\
\hline Bidasoa & $14+16$ & 2,580 & 51.5 \\
\hline
\end{tabular}

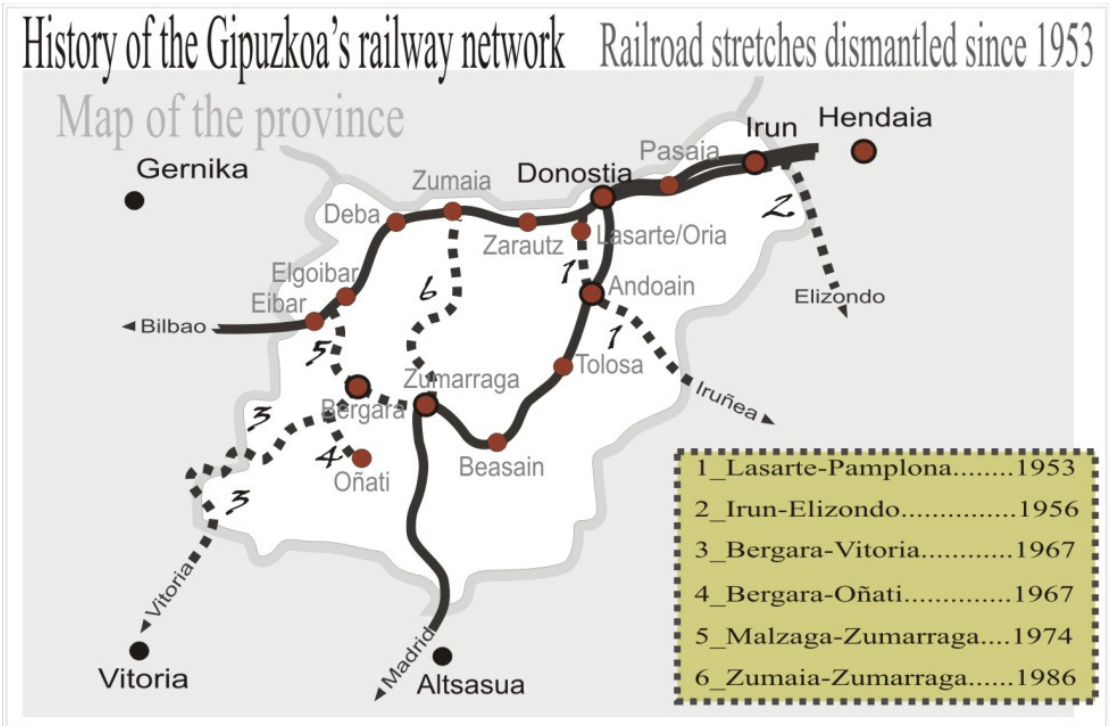

Figure 1: Gipuzkoa's railway network with active lines and dismantled tracks since 1953, in discontinuous line. 
"self-management" as the best guarantors of their preservation, so they can remain part of our collective memory, contributing from the present.

Therefore, we need a study to delve on the potential use of these resources, and then create the necessary mechanisms to make the heritage element work properly and to revert to society, to contribute again. Create a protocol for proactive conversion of industrial buildings and then, case by case, for specific development of these, adapting to the different characteristics and specificities of each case.

\section{The railway heritage (RH) and its putting in value (PV): concepts and methodology}

Addressing the question of how to proceed with the PV of the $\mathrm{RH}$, it seems to be key as a first step to tackle the problem of its protection. We can say that a wide range of issues are common to address the enhancement of industrial heritage, and therefore, the RH. However, and as we mentioned in previous lines, the railway heritage has a number of base characteristics that differentiate it and are, precisely, what make it a potentially active and dynamic resource that we have to know how to make the most of, differentiating it from other heritage enhancement strategies.

On the one hand, the degree of society sensitization and awareness about a concept or idea as recent as the "Industrial heritage as development generator asset” is still in process of maturation. But, even though we still have limited experience in the state on processes of putting in value the railway heritage resources, as social, cultural or/and economic ways successfully consolidated, it is true that initiatives aimed at alleviating this deficit have been undertaken in the Spanish state in recent years.

Rail lines are a transportation and communication infrastructure that spreads over a wide territory or different territories, acting as a nexus and serving as the main supporting element of territorial organization, and are capable of forming their own system which can lead to different subsystems or branches that complete the network. It is a heritage that is strongly linked to the territory it serves, and is adapted to the specificity and characteristics of the environment, both orographic and economic-productive, and also to the cultural background e.g. the different constructions linked to railway that were erected to serve it in the late nineteenth century and in early of the past. All these result in a great variety and display of regionalist architectural styles, very appropriate and beautiful with remarkable originality. We could say the same about the equally exemplary civil works, undertaken in that so complex period of time in the Spanish state, a lesson in resource optimization in times of scarcity and austerity that squeezed the ingenuity of their builders to design brave layouts to face the difficulties presented by the terrain with the means available.

Therefore, we can conclude that it is a heritage that is characterized not only by the circumstances of the time it was built in, but also by the territory it serves, that influences (paths, bridges and tunnels, buildings, styles, etc.) but also 
transforms. Thus, territory and railway form a combination that interacts inevitably, and in this interaction we also must base our enhancement strategy.

On the other hand, the fact that this set of assets that form the $\mathrm{RH}$ extends over a vast territory has made it difficult and sometimes impossible to carry out a process of effective management of the resource and, consequently, its conservation. We must not forget that an intervention on these elements often involves different administrations and entities, and requires a broader view, at different scales to understand the extension of the entire territorial framework in which it develops. Therefore, it is necessary to conceive the $\mathrm{RH}$ as a series of elements that are part of a set or a whole, understood and recognized like asset, linked with the most potential which undoubtedly is the ability to connect and communicate that has this special industrial heritage in the territory and hence, the ability to create nodes around it.

\subsection{Changing the ways to proceed}

A case by case rereading of the territorial mobility strategy seems necessary, which may come to recognize the railroad as an alternative again (in secondary or middle-distance network, lines of a length shorter than $100 \mathrm{~km}$ ), even in the valleys and counties through which already passed through. A mobility alternative more integrated to existing collective modes, offering an answer to the territorial problem of lack of social medium transport, safe, environmentally sensitive, comfortable, economical, operational (where part of the key is also on the interoperability between different modes)... interconnecting all strategic points of the territory in an acceptable time. We are talking about the city model and inevitably about the economic, energetic and social model.

When this group of built elements work together, they form a potential which aspires to more, is well structured, more advantageous and interesting when developing initiatives to attract private capital to invest in the heritage (one of our main goals) (fig. 2), and they pose a greater active on its whole. We aim to

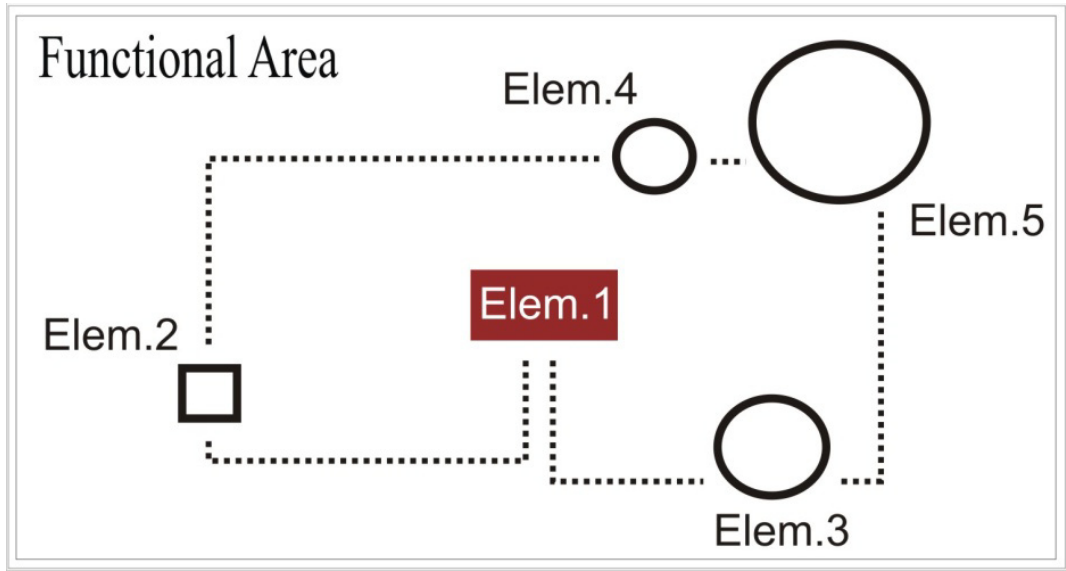

Figure 2: Synergy of active resources of the territory over the station (Elem.1). 
go beyond specific initiatives as "turn everything into a museum", which focus on a particular market niche often contested (though its topic is different), and only intervene on specific buildings. These initiatives are valid where the possibilities of the territory are limited or receptive market niche cannot be more varied. Nonetheless, it is a very limited generic model of intervention (although widespread) and directed to any historic building in the territory, which is comfortably adjusted to most of the heritage casuistry. We must admit that the method of "building a museum", an "interpretive centre", a "public library"... with public funds for each heritage element we want to preserve, has limited profitability and is on the verge of collapse. We understand that these solutions are perfectly applicable in most of the towns' heritage buildings (tower houses, palaces, factories, villages ...) and cripple much of the potential that stations might offer, where its greatest virtue and potential on the whole lie, as well as in the interconnection and mobility offered by buildings adjacent to a railway line.

The RH can serve the territory by the specialization of this, provided their effectiveness can be justified, not only economically, but also as a direct contribution to the development of the territory, through the specialization of the $\mathrm{RH}$ that serves the area and its potential assets, creating a synergy between the identified assets of the region and the own $\mathrm{RH}$ that could potentially serve them.

\subsubsection{Guidelines for action}

One of the most immediate steps towards the effective protection and proper management of railway heritage would be, on the one hand, the creation of an accurate digitized inventory of our railway heritage, which can be potentially extended and completed as our knowledge about this legacy increases, with public access to the dissemination of the acquired knowledge for all kinds of groups and users (display, query and spatial analysis of cartographic maps, data, graphics, photographs, etc.)

On the other hand, in conjunction with what has been developed previously, we believe it necessary to perform a diagnostic analysis that brings out the real state of conservation in which the asset is currently, as well as the analysis at different scales of the territory in which it is located and the historical, economical, social and cultural impact that it has had on that territory. This initial data will subsequently help us draw, in each case, adequate and appropriate strategies for the recovery and revaluation of the elements or set item in question.

We need a global analysis of railway heritage, a rethinking of the social model to which we aspire, superimposed on the model of mobility and infrastructures. How long do the axles and rail lines that were raised at the time in the area have left? (Can they be recovered now/partially/fully? For what purpose?) And we need to carry out another analysis of the context that gives meaning to these historical buildings, which will undoubtedly play a key role in securing the future of the whole of the stations in the railroad lines to study. Let us set the ideas in order:

1. Identification/Cataloguing/Inventory of the different heritage enhancement properties susceptible to be put in value. 
1.1 Creation of a database for registration.

1.2 Creation of the Railway Heritage digitized map.

2. Contextualization and characterization of the set element/item.

2.1 Analysis of the territory.

2.1.1 Connection: Design VS Orography: The Civil Engineering in the face of landscape.

2.2 Context History: Origin/Causes/Reasons/Process ... facing the current context. (Validity of the model?)

3. Analysis and assessment of the current state of tangible assets.

3.1 Analysis of the preservation status of the items.

Pathology, Diagnosis and Treatment.

3.2 Analysis of the current environment, place and location.

4. Strategies for preservation and enhancement of the Railway:

Identification of the potential, study and implementation of these alternatives.

4.1 The RH against the Territorial Planning Strategies:

4.1.1 Social Model and Mobility:

A) About the implementation of the historical axes of the existing lines in the area and the new territorial model.

B) The railroad as main support of a new urban growth, social model and as the main backbone of inter-territorial "sustainable" mobility.

4.2 Identification of the possible potential closest assets: territory resources

4.2.1 Potentialities of the place and its current reality.

A) Ideas and Opportunities: Find new fields of investment.

B) Put into Socioeconomic value: to show/rehabilitate/strengthen

4.2.2 Strategies active sociocultural revitalization:

A) Awareness and involvement/Network contributors.

B) Joint interaction dynamics in the region/province.

C) Promotion and diffusion tasks.

4.3 Heritage Socialization: Strategies of acquired knowledge dissemination, awareness, "musealization", etc.

This is a model to develop and expand. Currently we are working to define further and more completely these steps, as any intervention on the heritage is a multidisciplinary process, but we wanted to introduce it for discussion as a possible starting point of previous considerations, we understand to be taken, for future interventions of PV on RH.

\section{The railway stations and the territory}

\subsection{Context and approach: organic city and diffuse city}

The city grows and expands, as any living organism which progressively colonizes the territory. In recent decades, we have done it exponentially and often messily, since the benefits of a voracious speculative market exhausted the opportunities of a sustained growth with steadily consolidated and reflexive criteria. In summary, we can say that we have been running so much in pursuit of immediate benefit that such basic and root aspects have been neglected and now we start to take its toll. Moreover, cities experience cycles of expansion and 
contraction, as part of reactions to ever evolving natural cycles. And now we are in a period of contraction, which gives us, fortunately, some room to rethink the values with which we face the future of our cities and territory.

Since the mid-nineteenth, stations have become a point of reference in urban activity and are cores where much of the subsequent development of these cities is derived on and articulated, coinciding with the late nineteenth-century urban expansion of our cities and the subsequent industrialization process (e.g. the Dato street of Vitoria, formerly called Station Street and on which the main axes of the romantic city sprawl, also named the bourgeois expansion, were articulated) [6]. In the late nineteenth century, these buildings were considered literally "the city gates". It would therefore not be wrong to think that stations currently occupy privileged and strategic positions in most of our towns and cities.

Regarding the "organic city", the stations and their surroundings could be understood as "urban cell unit" or nodes, linked to the city by a "nervous system" or by an inter-territorial transport system called railway. The growth of communications promotes urban sprawl and the colonization of the territory, improves accessibility, bringing closer any kind of resources and also joins them. We understand the singularity of the territory as a key strategic factor in competitiveness and in the welfare of society.

Regarding the "diffuse city", we understand that a settlement sometimes can grow and develop to a point that exceeds the city limits, mixing with other communities and merging their limits. Such growth does not respond to local political parameters, and does not know about limits and abstract borders, as it is a more natural and intuitive growth that follows the laws that the territory sets, overcoming the local government. We could talk about the diffuse city in the Basque territorial model, in which the topography of rivers and valleys are what really mark the limits, otherwise nonexistent, in this successive and continuous sum of small population centres that have been growing, vertebrated by transport infrastructure, as the rivers were at the beginning and as roads and railways are now. But even now, in most cases, they follow these orographic features that form the Basque Country, up to the Cantabrian coast, giving shape to a diffuse city made up by the sum of tens of towns and referred to in urban fields as "Euskal Hiria” (Basque City).

The excessive growth and expansion of cities makes the centres lose strength, becoming progressively degenerated and ending up decentralized, something which does not have to be negative on a sustained territorial model. We talk about the organic defragmentation of the city into groups of autonomous interrelated communities. A multinodal city (multiple autonomous cores, but interconnected) which plays a key role in the diversification and specialization of territories. We talked about competitiveness of cities and functionality, (in a growth model supported by our whimsical and well-defined orography) where the main assets could be: Natural, cultural and productive resources and the social capital (and its training).

In short, we advocate the transformation of "cities and regions" (main characters of the immediate future) by means of areas of opportunity that 
facilitate the articulation of companies and universities as strategic projects (apart from traditional patterns of urban planning) to go from passive spaces to active spaces/smart territories/with their own identities and distinct characteristics... territories with personality, with their own competitive framework. It's time to put the territory in value through its resources.

We have historic buildings with heritage value and they are empty in what were once strategic activity nodes in the cities, attached to disused lines that were essential structure of the territory for more than a century. Returning to activate these lines with the different ways we can imagine, the path still remains as an important intermodal communication artery, so it can still be valid and therefore can bind this series of buildings with new uses, complementary to each other. If intermodal alternatives (part of the key to the competitive operation of the new "railroad" lies on intermodality, which is vital for the coordination between government and institutions to review the "Territorial Plans", trespassing often political and administrative boundaries in favour of the orography and territory) are introduced around these buildings, we obtain a real alternative and functional communication system around these buildings, which could house either businesses, firms, companies, research departments and development workshops or projects spaces and would identify with this new awareness of social and territorial mobility (supporting the "low carbon territories" alternative [7]).

We have to identify the active resources that exist within the functional area, in which they could be interested so as to achieve spaces in these heritage buildings, annexed to a sustainable transport line where they intercommunicate with each other. It represents an opportunity for a lot of new ideas and territorial resources that we have to identify and develop properly. In fact, following this pattern, it would be also possible to think of the absolute integration of disused railway buildings, through specialization and the development of a theme which is very present in a particular territory. Each node, or area of influence of each station, would focus on a particular subject or field, leading to specialized functional areas. If we integrate part of the railroad line with other stations into the same strategy, joining different functional areas that are, interrelated or completing each other, we are talking about territorial districts, e.g. cultural district, industrial district, gastronomic district, training district or research and development district (fig. 3).

So then, we need to create mechanisms that put these buildings in value and that can also attract innovative potential uses, strategic and necessary to the community they serve. We must be aware of the full potential of the RH and its buildings. The force (potential value) of these elements lies on:

1. The social potentials and human resources that can be mobilised and involved in favour of these patrimonial assets whose keys are: awareness and outreach.

2. The main asset that is the strategic location and mobility that comes from the fact of being adjacent to a track or major communications artery of the territory.

3. Be a set of heritage assets interconnected by a path of sustainable and social mobility, which has a future in it.

4. The large capacity for activation and centralization of asset resources of the area channelled by this strategic position that are assumed to possess. 
Stations can be receptacle of entrepreneurship, the creative centres of the main generators of wealth: cultural heritage assets ("pro-active" tourism industry, specialised, selective ...) packs of varied cultural offerings; socialization of knowledge and research as e.g. $\mathrm{R}+\mathrm{D}+\mathrm{i}$ departments....; Industry and trade, business incubators; information territorial centres; co-working areas, etc. (fig. 2).

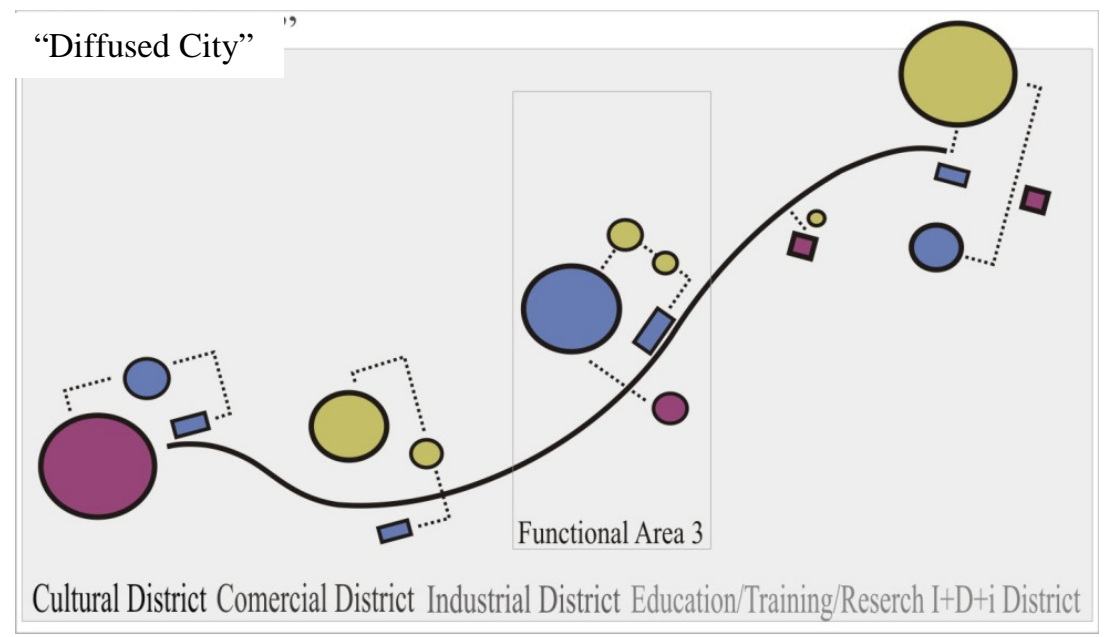

Figure 3: Stations as centralizer and as active dynamizator of the territory resources.

\section{From the deterioration of railroad transport to future opportunities}

After the Second World War, the trend that was ending with the undisputed hegemony in land transport that the railroad had until the early twentieth century was deepened, and already prior to the Spanish Civil War a large crisis was dragging the railway sector. The systematic closure of unprofitable branches or lines, reinforced the territorial disintegration of the interior of the peninsula and meant the consolidation of a trend towards Metropolitan concentration (19591975), which in 1975 showed more than 33\% of the Spanish population concentrated in the seven major cities of the state (this trend is also experimented towards the coast) [8].

However, the particular vulnerability of the Spanish economy concerning petrol (10 points above the European average), on which is heavily dependent just in the middle of an energetic model crisis, and the need of new territorial strategies for a society that is increasingly more aware of the fact that another model of social development is possible, gives the opportunity to reinvent themselves again, a new opportunity for the legacy of the railroad, the social transport par excellence, and its new modes.

Therefore, we must begin to see the interventions on the railway heritage from a wider point of view, in which all the influence area they are integrated 
into is gathered [9]. We must conceive it as a set of heritage elements, and try to act on the entire set, not giving up on preserving their main characteristic potentialities. So then, this heritage-infrastructure can act as backbone of the territory, articulating the various sources of resources and potentialities that a territory develops, based on intermodality and on the synergy of region assets, which can pivot around the railroad and can be materialized in stations (rereading of reusable and innovative spaces). These buildings are turned, valueadded spaces that are part of the collective heritage of the region, which maintains its historic and cultural legacy, the transmission and divulgation of values and knowledge and therefore, its character, identity mark in the reapplication of spaces, reinvention and excellence. We strongly believe in the preservation of this heritage by means of its active and dynamic putting in value, which allows the territory to claim the possibility of existence in an increasingly competitive market where, nevertheless, brave bets for the own culture, the authenticity and the alternatives that are disassociating from the general view that the voracious and increasingly globalized market offers, are really appreciated and indicate a way to undertake, in which certainly, the railway heritage has a lot to offer.

\section{Acknowledgements}

The first author wishes to thank the University of the Basque Country (UPV/EHU) and the Basque Railway Museum Foundation for their support of this research line recently opened.

\section{References}

[1] Salveson P., Northern Railway Heritage. (Prologue), Mottram H. Little Northern Books, 2009.

[2] Unzurrunzaga X., Jornadas sobre el sistema ferroviario Vasco. Summary of Papers. Gobierno Vasco. pp. 298-304, 1998.

[3] Eibar Philatelic Association, Nov.2009. http://egoibarra.com/eibar/eibarkoeraikuntza-eta-monumentu-nagusiak/eibarko-tren-geltokia/breve-historiadel-ferrocarril-en-el-pais-vasco

[4] Macias M.O. Ferrocarriles y desarrollo economico en el Pais Vasco 19141936. (ed) UPV/EHU. pp. 305-309.

[5] Olaizola J., Odriozola L., Arteche I. El ferrocarril del Urola, 1926-1986. (ed) Ayunt. Azpeitia. p. 107, 2002.

[6] Galarraga I., Unzurrunzaga X., Lopez de Aberasturi A., Azpiri A. Ensanches urbanos en las ciudades Vascas. Gobierno Vasco. pp. 176-179, 2002.

[7] Fariña. J., La ciudad orgánica/Colin Buchanan, Traffic in Towns. Urbanism, Territory, Landscape, Sustainability. http://elblogdefarina.blogspot.com.es/

[8] Nel lo O. Ordenar el territorio. El punto de partida: los retos territoriales y las bases de las políticas públicas. Colección Crónica, pp. 1-26, 2010.

[9] New York High Line recovery and enhancement project. Diller Scofidio + Renfro, 2006_2008. http://www.thehighline.org/design/high-line-design 